\title{
Mitigation of Accelerations Caused by Blast Loading Utilizing Polymeric-Coated Metallic Thin-Walled Cylinders
}

\author{
Jarrod Bonsmann $^{1}$ - W. L. Fourney ${ }^{1}$
}

Received: 27 March 2015 / Accepted: 9 May 2015/Published online: 27 May 2015

(C) Society for Experimental Mechanics, Inc 2015

\begin{abstract}
This paper investigates various means for mitigating acceleration experienced by passengers in vehicles subjected to blast loading. In order to conduct this study, smallscale experimentation on simulated vehicles was used. The explosives designated for this research are exclusively buried in saturated sand, which will act as the loading media for the simulated vehicles. Test plates used in this study vary in both size and geometry. When necessary, simple plate geometries are employed to investigate various mitigation parameters. Ultimately, much of the experimentation was conducted on simplified scaled versions of vehicles likely to be subjected to attack. This paper focuses mainly on mitigation through crushing of thin-walled cylinders, but also investigates the advantages of applying polymeric coatings to these dynamically loaded structures. Piezoelectric accelerometers are used in conjunction with high speed videography to collect test data. It was ultimately found that vast benefits are realized from using thin-walled cylinders to mitigate high acceleration values experienced from a blast load.
\end{abstract}

Keywords Blast mitigation - Small-scale explosive · Collapsible thin-walled cylinders

\section{Introduction}

Over the past decade, the increase in military fatalities due to use of buried explosives has created a demand for expanded knowledge in the field of target response to blast loading. When a vehicle experiences a blast load from a

Jarrod Bonsmann

bonsmann@umd.edu

1 Dynamic Effects Laboratory, University of Maryland, College Park, USA buried explosive the damage mechanisms for a passenger in the vehicle result from rapid accelerations [1] and large changes in momentum [2]. Blast loading (if survived) can result in traumatic brain injury (TBI) and violent injuries such as broken limbs. In recent years a growing number of people involved in buried explosive attacks have been diagnosed with TBI from the rapid acceleration of the targeted vehicle. As a result there is a strong need for the development of a device capable of mitigating the peak acceleration felt by passengers traveling in vehicles that are explosively loaded.

To address the need for knowledge pertaining to vehicle response under blast loading, the Dynamic Effects Lab at the University of Maryland has spent considerable time and resources investigating this event. Research has been conducted to better understand the mechanisms of the vehicle loading [3] and to determine various methods of reducing impulse and acceleration on them $[4,5]$. The main mechanism of the vehicle loading from a buried charge is the impact on the vehicle bottom by the soil that is thrown up by the detonated charge. This soil has been shown to be traveling in excess of Mach I, and when it is brought to rest on the bottom of the vehicle very large pressures develop [6].

As a result of the increased understanding of vehicle response to blast loading, the number of deaths as a consequence of buried explosive attacks has steeply declined as seen in Fig. 1 [7]. The most important development in vehicle design has been the utilization of Mine-Resistant Ambush-Protected (MRAP) vehicles which have angled bottoms that deflect the ejected soil in a sidewise direction.

By shaping the bottom of the blast loaded vehicles, violent injuries and immediate deaths due to the change in the impulse have steeply declined. However, since the passenger of the vehicle is surviving beyond the initial blast, the incidences of TBI have risen. For this reason, 
Fig. 1 MRAPs deployed in the field versus IED casualties from Ref. [7]

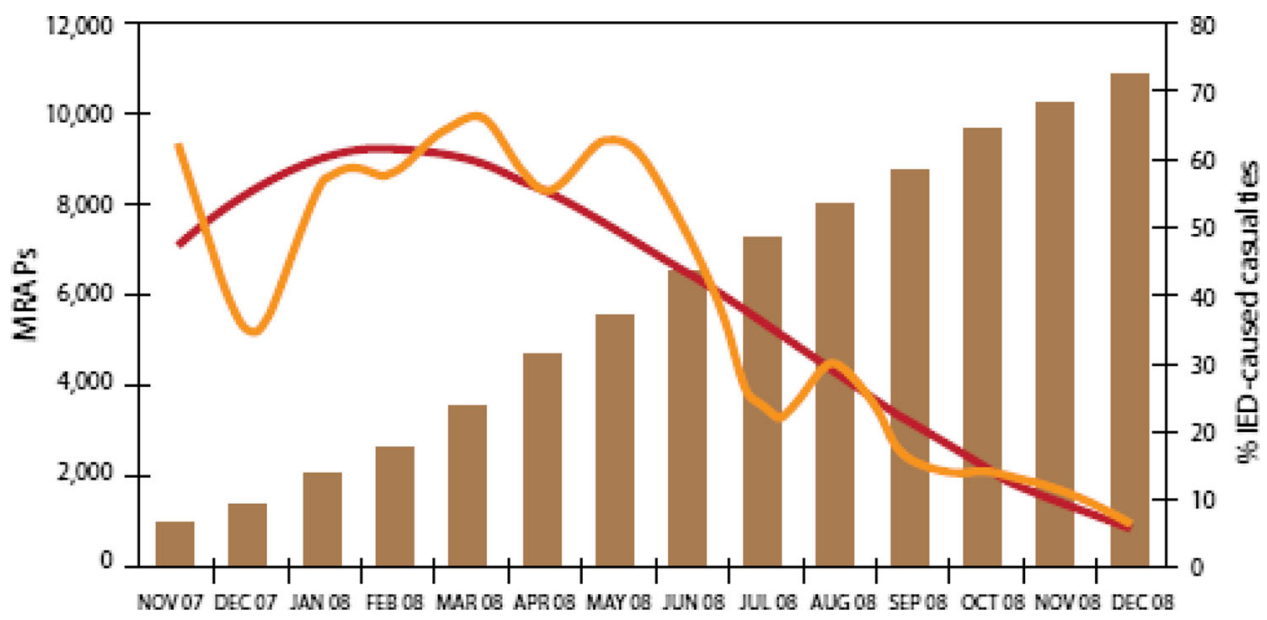

Cumulative number of MRAPs deployed

Percentage of IED-caused fatalities

Overall downward trend in percentage of IED-caused fatalities further knowledge is needed in the area of acceleration mitigation on blast loaded vehicles.

The primary focus in this paper is to study the acceleration mitigation effects of localized buckling (crushing) of thin-walled cylinders. Thin-walled cylinders have long been studied in the field of energy absorption. There exists a plethora of research detailing the benefits of adding tubes to structures to absorb impact energy. For lower speed impacts both Alghamdi and Yuen et al. give an overview of a multitude of collapsible structures for use as energy absorbers [8, 9]. A number of studies have been performed characterizing the benefits of crushing tubes laterally for impact protection $[10,11]$ and quite a few studies have been conducted to classify the energy absorption of composite tubes [12-14]. Additionally there have even been some studies, both numerical and experimental, where tubes or thin-walled structures of multiple geometries made of various materials (both metallic and composite) have been studied for use as sacrificial claddings for structures that undergo blast loading [15-17]. All of this research points to the fact that thin-walled structures, in a variety of geometrical patterns made of all kinds of materials, have numerous benefits to offer when it comes to protecting structures from blast loads. There is a lack of information, however, involving the benefits of using thin-walled cylinders as a technique for mitigating acceleration.

Much effort has been spent [18, 19] in researching the mechanical behavior of polymeric materials used for coatings in blast applications, especially the material polyurea. It has been found that under very high strain rates the polymer loses its "rubbery" mechanical behavior and begins acting more like leather. This characteristic allows the polymer to increase toughness under high strain rates, making it more effective at absorbing blast loads. In addition to characterizing the high strain rate mechanical properties of polyurea, the polymeric coating has been applied to panels that undergo blast loading in order to determine what benefits it has as a protective layer to prevent deformation and damage to structures. Major benefits in protection of structures due to polymeric or elastomeric coatings have been found when applied to composite structures [20]. On the contrary, when applied to steel plates (keeping the areal density constant) it was found that plain steel plates absorb the blast more effectively than those coated with polyurea [21].

Finally, some preliminary work has been performed in previous years in the Dynamic Effects Lab that shows that coating the hull of a vehicle that undergoes blast loading is an effective means for acceleration mitigation, though it should be noted that the areal density of the plate was not kept constant. Additionally, small-scale acceleration mitigation testing was performed on simulated vehicles utilizing a number of mitigation techniques such as deformable coils and crushable tubes [22]. An in-depth comparison between the cited work and the current work will be made in the discussion section.

The testing facilities at the University of Maryland are equipped to perform small-scale explosive experimentation. Small-scale experimentation has a number of advantages over large-scale experimentation; they are less expensive to conduct and also can be conducted in a much shorter time frame. In addition it has been shown in previously published works [23-25] that small-scale experimentation can accurately represent the response of a target to an explosive detonation. 
The scaling factor is determined by taking the cubed root of the ratio of the full-scale mass of the explosive over the small-scale mass of the explosive.

$S F=\left(\frac{\text { mass }_{\text {full-scale }}}{\text { mass }_{\text {small }- \text { scale }}}\right)^{\frac{1}{3}}$

In this work the full size charge was taken to be $4.536 \mathrm{~kg}$ of explosive. In the majority of the research in this paper, the small-scale experiments used an explosive mass of $4.4 \mathrm{~g}$, resulting in a scaling factor of approximately ten. All length and time dimensions were scaled using this factor. The small-scale lengths and times are determined by dividing the full-scale values by this factor while the small-scale accelerations are determined by multiplying the full-scale values by this factor.

The research reported in this paper is intended to aid in the design of vehicles that will minimize the amount of damage to a passenger traveling within the vehicle that undergoes explosive loading.

In order to accomplish the goals of the research, the primary experimental technique employed is small-scale explosive testing. This experimentation method is used to investigate means of acceleration mitigation by the crushing of thin-walled cylinders. A number of geometric properties of thin-walled cylinders, such as height, wall thickness, and outer diameter are all considered. In addition to geometric properties, the number of cylinders and, to a minor degree, the cylinder material is also examined. The majority of the experiments were conducted on plates fabricated to be scaled-down versions of vehicles likely to undergo blast scenarios. At the conclusion of the research it was determined that there are great benefits to using thinwalled cylinders to mitigate the acceleration of a passenger travelling in a vehicle that is subjected to loading by the detonation of a buried mine.

\section{Experimental Method}

In order to perform a successful explosive experiment, a wide array of equipment is needed. Instrumentation to obtain measurements of acceleration, displacement, and time are all required to generate the data necessary for proper analysis. In addition, equipment is needed to perform the blasting itself. The accelerometers used in this paper were manufactured by PCB Piezotronics Inc. The accelerometers chosen were model 350B04 with a measurement range of $\pm 5000 \mathrm{~g}$ s. A PCB Piezotronics Inc. signal conditioner, model 483A and two LeCroy oscilloscopes, model numbers 9314AM and 9315AM, were employed with the accelerometers for data acquisition.

For visual tracking, a Phantom v12.1 high speed camera equipped with a Tamron $28-75 \mathrm{~mm}$ variable focus lens was used. The Phantom software enables the user to create a document wherein the displacement of a specific point on the target and its associated time can be specified. Each high-speed video was analyzed using the Phantom software and Microsoft Excel was used to create displacement versus time graphs.

To create the blast, plastic explosive sheet (Deta Sheet from Omni Explosives) was used in conjunction with an exploding bridge wire detonator manufactured by Teledyne Technologies. The detonator contains a small amount of explosive that when combined with the plastic Deta Sheet, accounts for the total mass of explosive reported for each experiment. The explosive charge is formed and placed in a plastic sleeve to insure repeatability in charge geometry from experiment to experiment. The firing system responsible for detonation is connected to the explosive, high speed camera and oscilloscopes so that when the firing system is discharged each of the recording devices trigger at the same time so that they may record the explosive event simultaneously.

The actual blast experiment takes place in a tank constructed from steel with outer dimensions of $1.5 \mathrm{~m}$ long by $1.5 \mathrm{~m}$ wide by $0.6 \mathrm{~m}$ deep. The tank is filled with sand and is capable of being flooded with water from the bottom up. A schematic of the blast testing equipment is shown in Fig. 2.

There are a number of steps that must be taken in order to prepare for each blast experiment. Because the smallscale nature of the experiment, test preparation is performed with the utmost care as a small error in any of the dimensions can result in large errors in the experimental results. Each of the steps mentioned in the next paragraph are explained in more detail in a previously published paper [26].

The initial sand bed preparation consists of creating a $1.2 \mathrm{~m}$ by $1.2 \mathrm{~m}$ elevated and compacted sand platform in

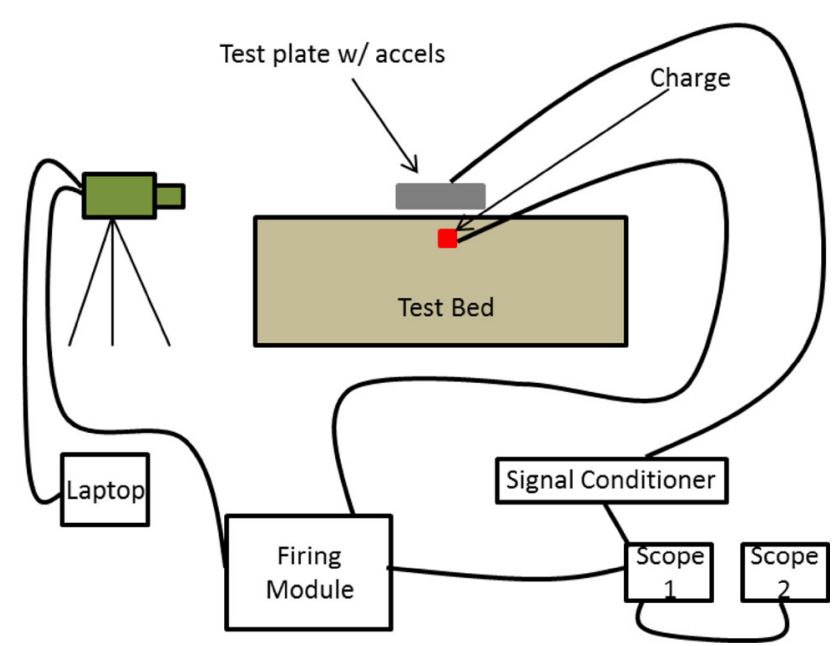

Fig. 2 Schematic detailing blast test equipment set-up 
the center of the test bed. The height and compaction of the sand bed is controlled and repeatable. Once created, the explosive charge is buried in the sand bed at a location directly under the center of the test plate.

For all of the experiments in this paper a depth of burial (DOB) corresponding to $10 \mathrm{~cm}$ full-scale is used. In most cases the small-scale DOB is $10 \mathrm{~mm}$ since, as previously mentioned, the scaling factor for this series of experiments was determined to be approximately ten. DOB is defined here as the distance between the top surface of the charge and the surface of the sand.

The next step is to locate the plate and fix its stand-off distance (SOD). SOD is defined as the distance between the top of the sand and the bottom of the target plate. Depending on the plate characteristics, the test plate may either be placed on a set of blocks that are machined to have the exact height of the specified SOD (Fig. 3), or suspended above the sand on chains attached to the ceiling.

Once prepared, the test bed is saturated from the bottom up. The water height which determines the amount of saturation is controlled and repeatable. The final set-up for a blast experiment is shown in Fig. 3 .

Once the bed has saturated fully, cables are connected to the accelerometers on the plate. The high speed camera is aligned and the image adjusted. Then a dummy charge is fired to make sure all data acquisition systems are functioning properly. After the dummy round, the charge lead wires are connected to the firing module and the charge is detonated. Upon detonation the video is examined and saved using the Phantom software. The acceleration signal

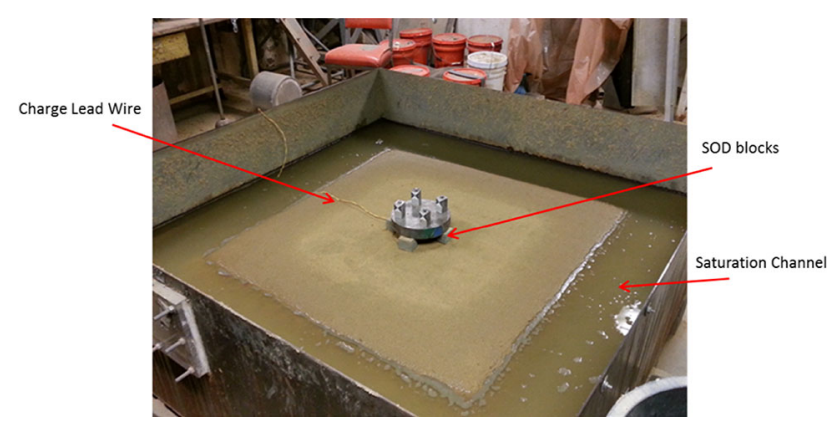

Fig. 3 Fully prepared blast experiment sand bed is downloaded from the scopes and loaded into the UERD Tools (software developed by NSWC-Carderock Division) program to allow for data analysis.

Ideally, the plates under study should reflect the geometric properties of the vehicles that are regularly targeted by explosive devices and the rectangular plates used in the first part of the program had the scaled down dimensions of some of those vehicles (MRAPS). The outer dimensions of the plates used were $45.72 \mathrm{~cm}$ by $30.48 \mathrm{~cm}$.

A simplified hull/frame combination was used to represent the vehicle. The hull, or bottom, of the simulated vehicle is responsible for capturing all of the ejecta. It is important that the hull of the vehicle be as rigid as possible so that the "flapping" of the plate (upon blast loading) is minimized. Creating a rigid hull will ensure repeatability of contact in between the hull and the frame. For this reason the hull is made from two plain woven carbon fiber plates connected with an aluminum (6061) star-shaped bracing pattern to increase bending moment of inertia. It should be noted that the experimental environment is incredibly harsh, and that each experiment requires the hull to be violently loaded. Due to the extreme loading conditions, the number of tests that were able to be run was limited before the hull began to delaminate. The expense of the hull further limited this number.

The frame, or top, of the simulated vehicle represents where the passengers of an actual vehicle would sit; this is where the accelerometers and tracking targets are placed, as this is the portion of the vehicle that it is necessary to protect from very large accelerations. The frame was made out of a steel plate with the interior removed to create a uniform wall thickness around the rectangular edge. The hull to frame mass ratio was kept close to one. The specific simulated vehicle test characteristics are shown in Table 1.

In between the hull and frame, there is (in any given experiment) either a series of thin-walled cylinders made from metal of various geometric properties, or air. Two different methods for setting the SOD of a test plate were used-stand-off blocks and/or hanging the plate from chains. The chains were normally used for heavier plates and blocks used for the lighter plates. In some cases, a combination of the two methods was used. The first portion of the mitigation study involved creating baseline data

Table 1 Material and geometric characteristics of simulated vehicle test plates

\begin{tabular}{|c|c|c|c|c|c|c|c|c|c|c|c|}
\hline $\begin{array}{l}\text { Frame } \\
\text { material }\end{array}$ & $\begin{array}{l}\text { Frame } \\
\text { length } \\
(\mathrm{mm})\end{array}$ & $\begin{array}{l}\text { Frame } \\
\text { width } \\
(\mathrm{mm})\end{array}$ & $\begin{array}{l}\text { Frame wall } \\
\text { thickness } \\
(\mathrm{mm})\end{array}$ & $\begin{array}{l}\text { Frame } \\
\text { thickness } \\
(\mathrm{mm})\end{array}$ & $\begin{array}{l}\text { Frame } \\
\text { mass } \\
(\mathrm{kg})\end{array}$ & $\begin{array}{l}\text { Hull } \\
\text { material }\end{array}$ & $\begin{array}{l}\text { Hull } \\
\text { length } \\
(\mathrm{mm})\end{array}$ & $\begin{array}{l}\text { Hull } \\
\text { width } \\
(\mathrm{mm})\end{array}$ & $\begin{array}{l}\text { Hull } \\
\text { thickness } \\
(\mathrm{mm})\end{array}$ & $\begin{array}{l}\text { Hull } \\
\text { mass } \\
(\mathrm{kg})\end{array}$ & $\begin{array}{l}\text { Total mass } \\
\text { w/targets } \\
(\mathrm{kg})\end{array}$ \\
\hline Steel & 457.2 & 304.8 & 76.5 & 9.525 & 7.1 & $\begin{array}{l}\text { Carbon } \\
\text { fiber } \\
\text { w/6061 } \\
\text { star }\end{array}$ & 457.2 & 304.8 & 45.7 & 6.5 & 14 \\
\hline
\end{tabular}


where only air separates the hull and the frame. For these experiments, the hull rested on stand-off blocks and the frame hung on chains a specified distance from the hull.

The next and most common test set-up involved attaching the thin-walled cylinders only to the hull. In this situation, as in the air gap experiments, the hull rests on the blocks and the frame is lowered on the chains until the frame just makes contact with the thin-walled cylinders. This set-up prevents the stand-off block from supporting too much weight - causing them to sink in the saturated sand and changing the SOD. For a few experiments, the thin-walled cylinders were attached to both the hull and the frame. These experiments only required the use of the chains to set the SOD of the test plate.

Each test plate had four targets attached to the frame. One target was located on each corner of the frame to enable tracking using the high speed camera. In addition, each test frame had two accelerometers located along a diagonal line connecting the left front portion of the frame with the rear right portion. These acceleration signals were averaged to give the final readings reported in the results section. The accelerometers and the visual targets can all be seen in Fig. 4.

Various experiments required the use of thin-walled cylinders that could not be found commercially. In these circumstances the cylinders were made using shim stock. To create a cylinder of specified thickness, a sheet of shimstock was purchased having the required thickness. The sheet was then cut to the required dimensions, rolled into a cylinder, and the seam adhered with a high-strength double

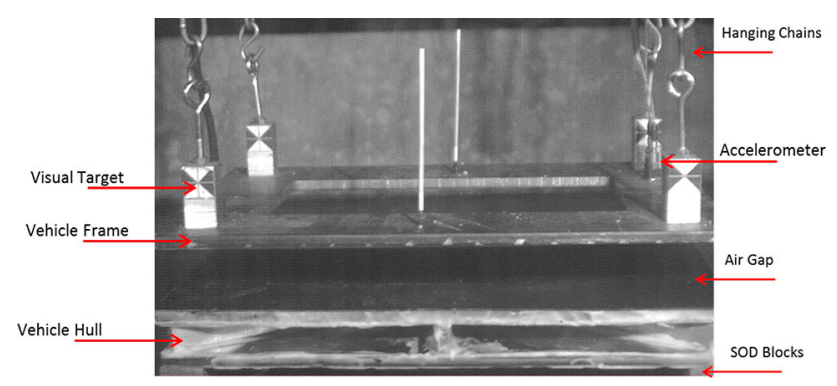

Fig. 4 Test set-up for no mitigation experiments sided adhesive tape manufactured by $3 \mathrm{M}$ called VHB tape to create the test piece.

Certain experiments involved applying various amounts of polyurea as a coating material to the thin-walled aluminum cylinder. The polyurea used for this research was manufactured by Specialty-Products, Inc. and is designated HM-VK. It is an ultra-high strength hand-mixable polyurea elastomer. This specific polyurea was chosen for its high gel-time of $18 \mathrm{~min}$ and lower viscosity. These two properties allow the polyurea to be used to accurately create test specimens for this study. A description of the properties of the polyurea when dry (as obtained from the HM-VK technical data sheet) is shown in Table 2 .

The thin-walled cylinder was created from aluminum shim stock with a polyurea coating applied onto the outer walls. A specific mass of polyurea for each experiment is mixed and applied to the prepared shim stock surface using a small paint brush. The low viscosity of the polyurea allowed for the material to settle on the surface of the metal and create a more or less uniform coating thickness (disregarding the very edge). Each experiment was conducted with a pre-determined mass ratio of polyurea to the aluminum substrate.

\section{Experimental Results}

\section{Height of Target (HOT)}

In this paper the height of the target is defined as the distance between the top of the hull and the bottom of the frame (or the distance between the two plates). Since different lengths of cylinders were used between the hull and the frame it is important to know how acceleration, kinetic energy, and impulse changes as the distance between the hull and frame is increased. The initial experiments in this series were therefore conducted with nothing between the hull and frame and with the distance between the hull and frame increasing. The various HOT's used were 25,38 , and $50 \mathrm{~mm}$ and one experiment was run at each condition. Following this, four experiments (including one repeat experiment at a HOT of $25 \mathrm{~mm}$ ) were run with standard aluminum beverage cans separating the hull and the frame
Table 2 Polyurea dry properties for HM-VK [27]

\begin{tabular}{ll}
\hline DRY properties @ 125 mils $(1.67 \mathrm{~mm})$ & \\
\hline Tensile strength ASTM D412 & $6671 \mathrm{PSI}(46.36 \mathrm{mpa})$ average \\
Elongation ASTM D412 & $506 \%$ Average \\
Hardness (shore A) ASTM D2240-81 & $95(0 \mathrm{~s})$ \\
Hardness (shore D) ASTM D2240-81 & $48(0 \mathrm{~s})$ \\
Modulus 300 \% ASTM D412 & $1395 \mathrm{psi}(9.7 \mathrm{mpa})$ \\
Service temperature & -30 to $+250{ }^{\circ} \mathrm{F}\left(-34\right.$ to $\left.+121{ }^{\circ} \mathrm{C}\right)$ \\
\hline
\end{tabular}




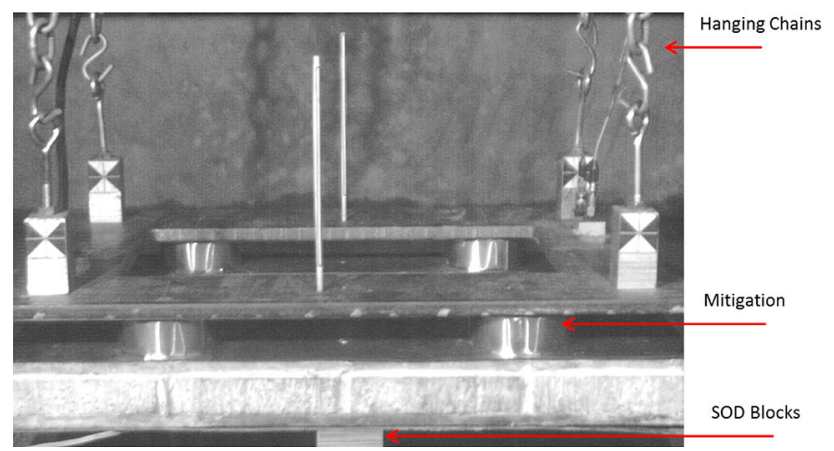

Fig. 5 Test set-up with mitigation attached to hull only

and the cans were only attached to the hull. Then three experiments using the same geometry cans were conducted with the cans attached to both the frame and the hull, resulting in an accordion type stretching following the initial crushing. All of these experiments had a $4.4 \mathrm{~g}$ charge, a SOD of $40 \mathrm{~mm}$, and a DOB of $10 \mathrm{~mm}$. Four aluminum cans located as shown in Fig. 5 with an outer diameter (OD) of $66 \mathrm{~mm}$ and an inner diameter (ID) of $65.8 \mathrm{~mm}$ were used to mitigate the accelerations.

The acceleration signals from each experiment were analyzed and averaged. Figure 6 shows sample accelerometer signals (no mitigation, mitigation attached the hull only, and mitigation attached to both the hull and the frame) from this series. This plot compares the signals from the accelerometers from the experiments for each scenario at a HOT of $25 \mathrm{~mm}$. In order for the data to be considered valid, the displacement versus time resulting from the camera tracking of visual targets on the plate (and the accelerometers themselves) must show strong correlation with the displacement versus time curve that is developed through the second integration of the acceleration signal. An example of acceptable agreement between signals is shown in Fig. 7. Figure 8 gives an overall view of the results obtained and Fig. 9 is a zoomed in view of the benefit of attaching the cylinders to the frame and the hull versus just attaching the can to the hull.
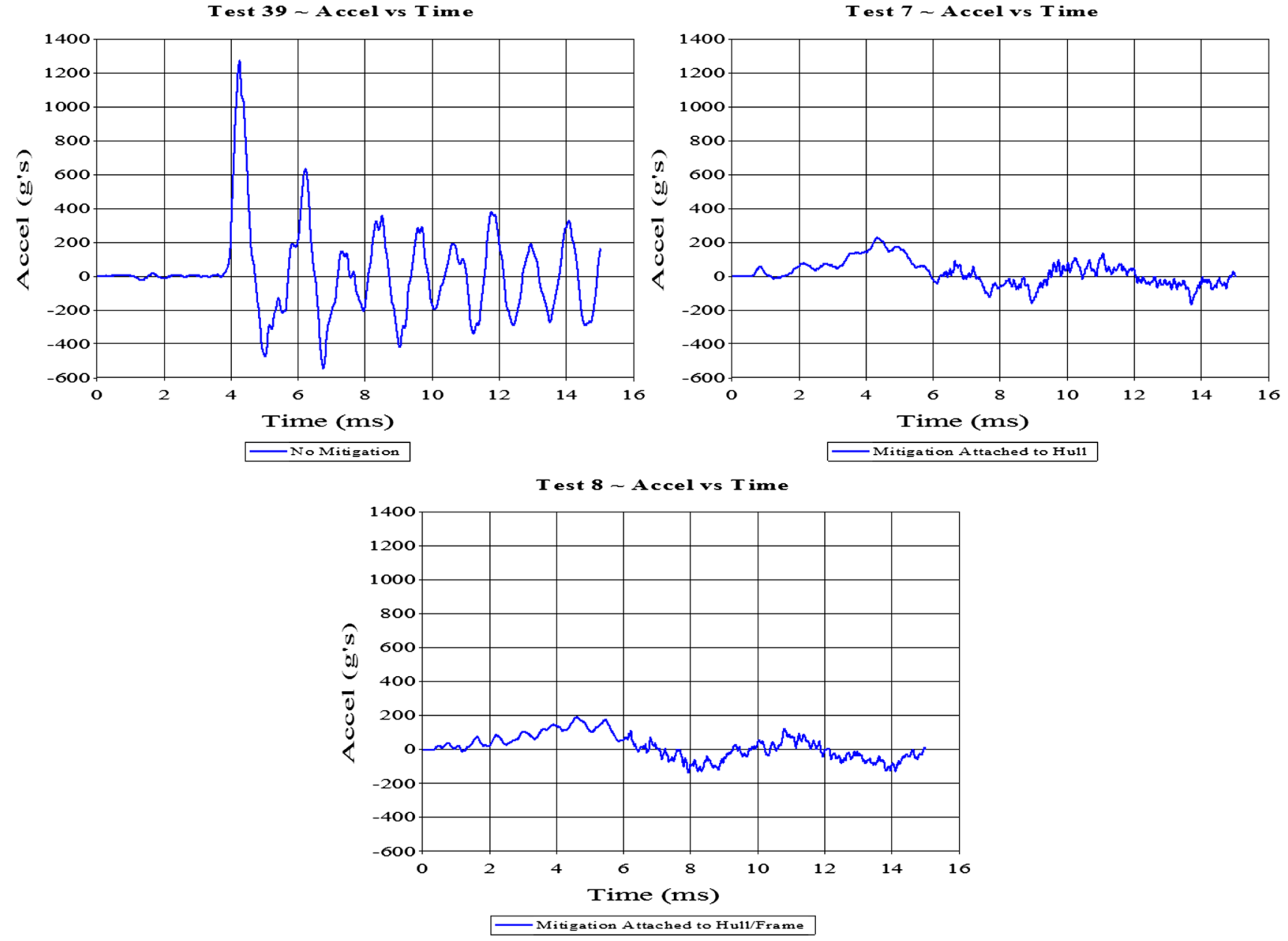

Fig. 6 Comparison of frame acceleration with no mitigation (top left), mitigation attached to the hull only (top right) and mitigation attached to the hull and the frame (bottom) 


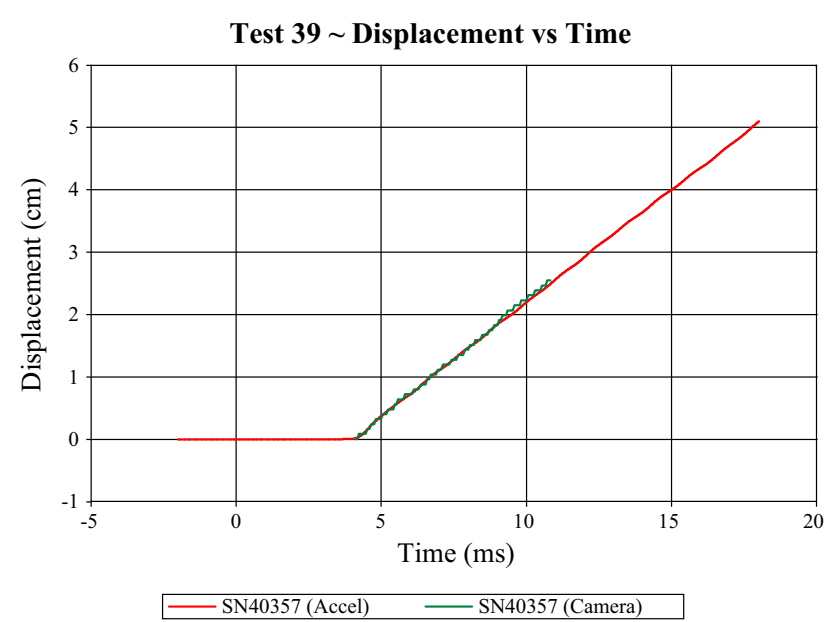

Fig. 7 Displacement versus time comparison for data obtained through high-speed camera and accelerometer

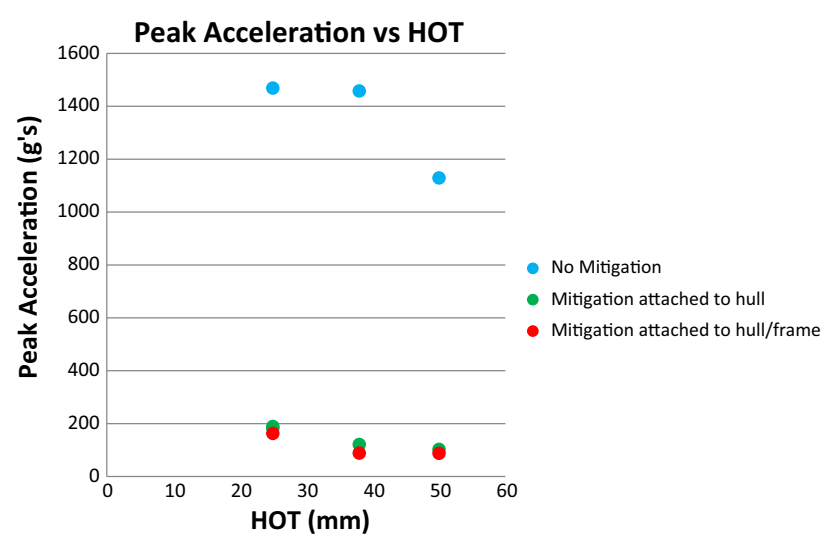

Fig. 8 Peak acceleration versus height of target for no mitigation and mitigation scenarios

Looking at Fig. 8, as the height of the target (the distance between the hull and frame) increases the peak acceleration decreases. Doubling the HOT from 25 to $50 \mathrm{~mm}$ decreased the peak acceleration from about $1450 \mathrm{~g}$ s to about $1120 \mathrm{~g} \mathrm{~s}$ for the control case. At $25 \mathrm{~mm}$ the use of crushing cans reduced the acceleration from 1450 to around $185 \mathrm{~g} \mathrm{~s}$ when attached to the hull only. From Fig. 9, it is seen that attaching the crushing cans to both hull and frame results in a further drop of acceleration level to around $162 \mathrm{~g}$ s. This trend was seen in all experiments at the three values of the HOT investigated.

Using the cube-root scaling law and scaling this result up to full-scale, for this series of experiments, in the worst case scenario (no mitigation, $25 \mathrm{~cm}$ HOT full-scale) a passenger would experience an acceleration of $150 \mathrm{~g} \mathrm{~s}-\mathrm{a}$ fatal level. Using the hull/frame attached cans at a HOT of $50 \mathrm{~cm}$ full-scale, a passenger in the vehicle would experience around $9 \mathrm{~g} \mathrm{~s}$-a far more survivable level.

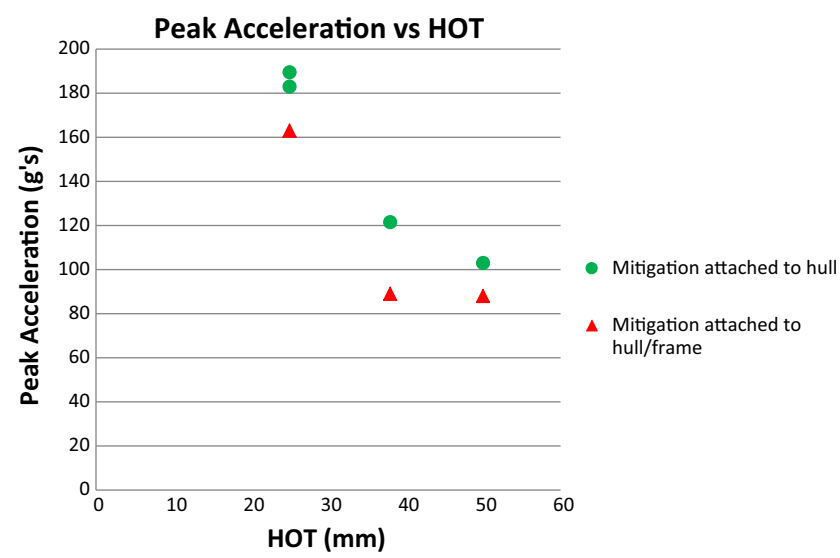

Fig. 9 The effect of attaching cylinders to the hull and the frame

\section{Number of Cylinders}

In order to determine the effect of adding more cylinders between the hull and the frame, two additional experiments were conducted, one with six cylinders and a second with eight cylinders. The HOT used was $25 \mathrm{~mm}$ with a charge of $4.4 \mathrm{~g}$, a SOD of $40 \mathrm{~mm}$, and a DOB of $10 \mathrm{~mm}$. The cylinders were aluminum as before with an OD of $66 \mathrm{~mm}$ and an ID of $65.8 \mathrm{~mm}$. Each experiment was conducted with the cylinders attached only to the hull. A HOT of $25 \mathrm{~mm}$ was the worst-case situation of the three studied previously and it was desired to use that HOT in the rest of the experiments for two reasons. The primary reason comes from the fact that vehicles in the field face situations where vehicle roll-over is a very real concern. To combat this, it is often desired that the vehicle center of gravity be as low as possible. By testing the $25 \mathrm{~mm}$ high cylinders, a determination of the effectiveness of the mitigation techniques for a low center of gravity vehicle can be made. Another reason for testing the $25 \mathrm{~mm}$ cylinders comes from the fact that the acceleration levels (with the mitigating cylinders) for the $50 \mathrm{~mm}$ HOT experiments are simply too low to be accurately measured. Looking at the acceleration signals from the $50 \mathrm{~mm}$ HOT experiments (see Fig. 10) it might be said that the peak acceleration comes from low frequency vibrations of the frame as opposed to a sharp acceleration peak resulting from hull to frame contact. Because of the extremely low acceleration levels of the $50 \mathrm{~mm}$ HOT, a more meaningful study of the effect of increasing the number of cylinders can be made at the $25 \mathrm{~mm}$ HOT.

An illustration of how the acceleration envelope changes with the increase in mitigating cylinders is seen in Fig. 11. One of the interesting results is the general shape of the acceleration pulse. Looking at Fig. 11 (which gives acceleration time data from the experiments with four, six, and eight cylinders) it appears as if there is a strong element of low frequency frame vibration added to the 

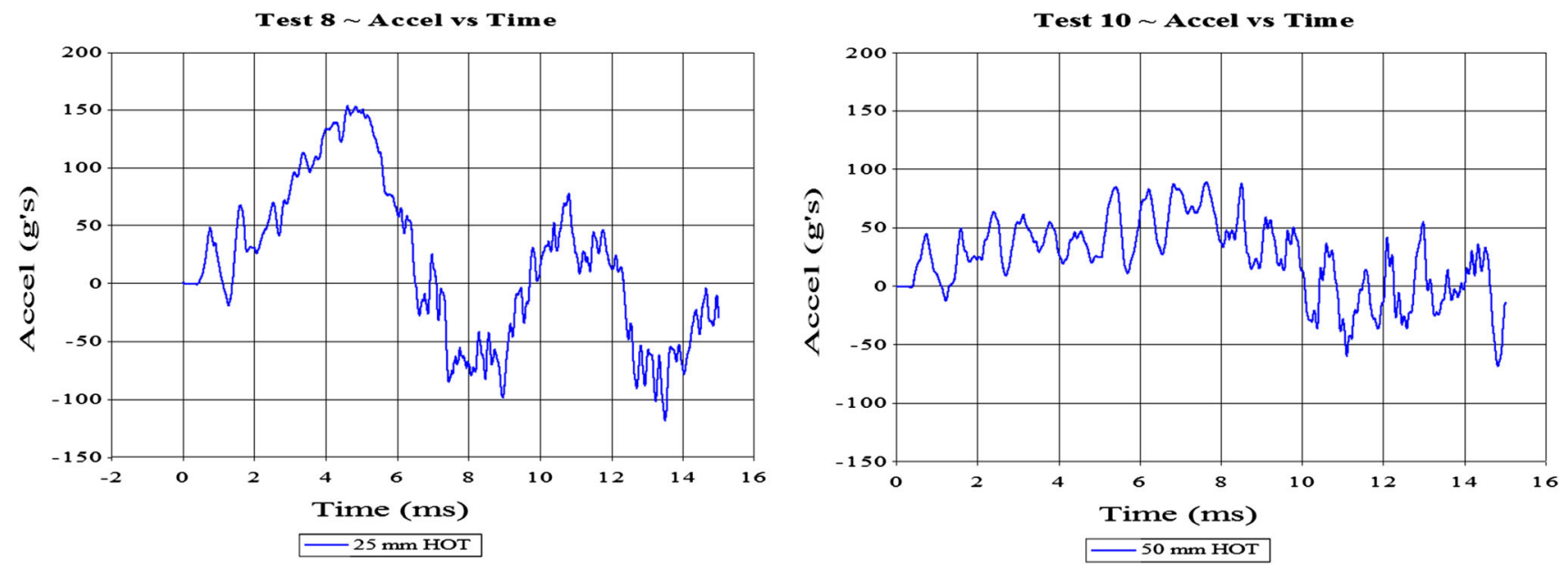

Fig. 10 Comparison of acceleration signals for $25 \mathrm{~mm}$ HOT (left) and $50 \mathrm{~mm}$ HOT (right)
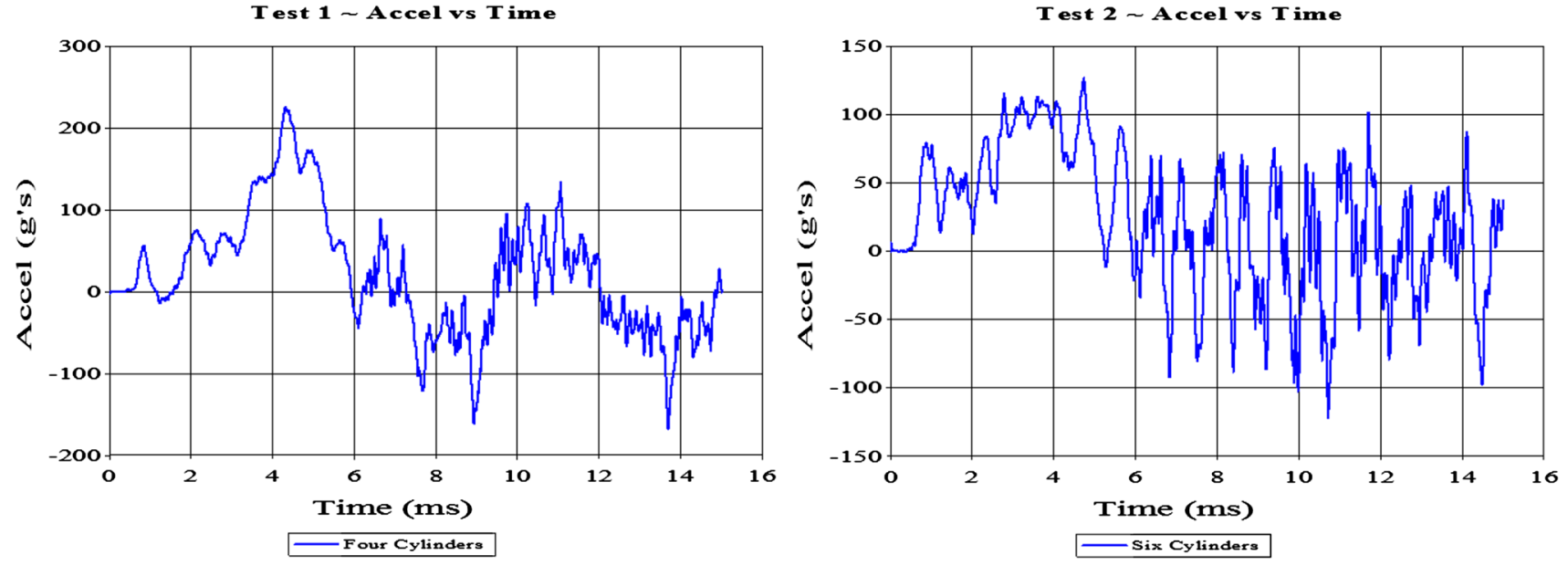

Test $3 \sim$ Accel vs Time

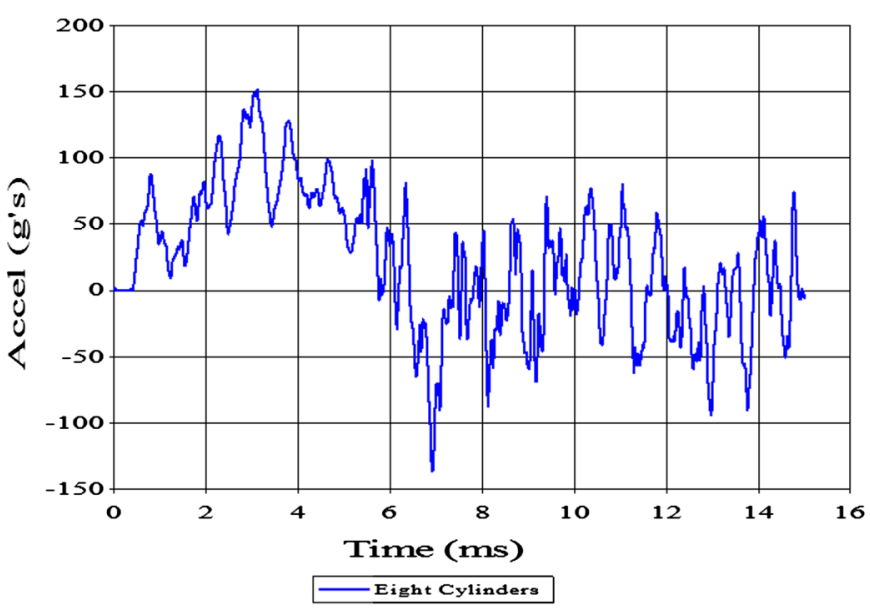

Fig. 11 Comparison of acceleration signals for four, six, and eight cans

acceleration signal. This is backed up by high-speed video evidence which shows the frame visibly flexing and rebounding during the initial loading stages. When the cylinder number increases, that low frequency vibration seems to be decreased or eliminated. The red signal represents the four can experiment, with the blue and green 


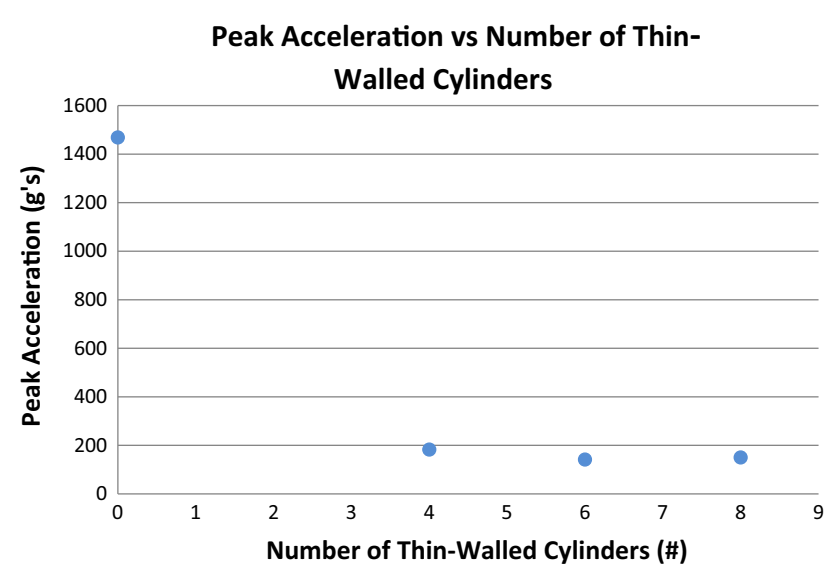

Fig. 12 The effect of varying the number of thin-walled cylinders on peak acceleration

signals representing six and eight cans experiments respectively. After the initial peak acceleration, the four can experiment has a substantial vibration signal at a defined frequency. This vibratory characteristic does not appear in either of the other experiments. This would be expected in that for the four can experiment there are vibrational constraints at only four points (the four cylinders), which increases as the number of cylinders increases. The more points at which the frame is constrained the less one would expect these large vibrations.

The effect of increasing the number of cylinders on the peak accelerations measured is given in Fig. 12 which shows peak acceleration plotted against the number of cylinders.

It appears as if there is only a slight reduction in peak acceleration due to increasing the number of cylinders. Full-scale acceleration levels decrease from around $18 \mathrm{~g} \mathrm{~s}$ to somewhere in the neighborhood of 14-15 $\mathrm{g} \mathrm{s}$. After the initial decrease at six cylinders, the peak acceleration increases with the addition of two more cylinders (to eight). As mentioned previously, the number of experiments run was limited by a number of factors; for this reason we were unable to develop an experimental data scatter envelope, but believe that these slight changes are a result of data scatter. Additionally, as mentioned previously, it looks like increasing the number of cans may damp out low frequency frame vibration; significantly reducing the duration of time a passenger might experience high levels of acceleration.

\section{Diameter Study}

To study the effect of a change in diameter of the mitigating cylinders, two additional experiments were conducted. In this series, in addition to the control experiment where no mitigation was present and the experiment with a cylinder with an ID of $65.8 \mathrm{~mm}$ and an OD of $66 \mathrm{~mm}$, two additional experiments were conducted with the same cylinder wall thickness and material but with different OD's and ID's. In one experiment the OD was $73 \mathrm{~mm}$ and the ID $72.8 \mathrm{~mm}$ while for the other the OD was $53 \mathrm{~mm}$ and the ID was $52.8 \mathrm{~mm}$. The two additional experiments therefore bracketed the experiment already conducted. As before the HOT was $25 \mathrm{~mm}$ and the DOB was $10 \mathrm{~mm}$ and the SOD was $40 \mathrm{~mm}$ with the standard charge size of $4.4 \mathrm{~g}$. Four cylinders were used in each of these experiments and the cylinders were attached only to the hull.

A comparison of the acceleration versus time signals is presented in Fig. 13 and the peak acceleration versus outer diameter is presented in Fig. 14. Looking at Fig. 13, all acceleration signals have the same low frequency vibrations present as pointed out above (there were only for points of constraint). This supports the previous hypothesis that, when excited from the four points of contact of the thin-walled cylinders, the frame vibrates at a low frequency resulting in a relatively high acceleration level. The red line represents the smallest outer diameter, the blue line represents the middle outer diameter size, and the green line portrays the acceleration of the simulated vehicle frame that utilized the cans with the largest outer diameter.

From Fig. 14 it can be seen that for the $53 \mathrm{~mm}$ OD cylinder, the acceleration of the frame decreases from the baseline value of $1470 \mathrm{~g}$ s to around $275 \mathrm{~g}$ s. The acceleration continues decline for the $66 \mathrm{~mm}$ OD where the acceleration drops to around $180 \mathrm{~g}$ s. For the larger OD cylinder $(73 \mathrm{~mm})$ it appears as if the acceleration value levels off.

\section{Wall Thickness Study}

To test the effect of wall thickness on acceleration, the test preparation is a bit more involved. In previous experiments, beverage cans with the necessary geometric characteristics were used as the mitigation material. This provided a cylinder, uniform in wall thickness, with a seamless construction. Beverage cans of varying wall thicknesses could not be found, so thin-walled cylinders of varying wall thicknesses had to be constructed out of shim stock.

The initial experiment of this series involved replicating a previously performed experiment, but this time performing the test with a shim stock cylinder as opposed to a commercially produced cylinder. In addition to this comparison, two additional experiments were completed with different wall thicknesses from the original experiment. In all, three additional experiments were conducted. All three experiments used cylinders with an OD of $66 \mathrm{~mm}$. One used shim stock with a thickness of $0.1 \mathrm{~mm}$ to duplicate an 

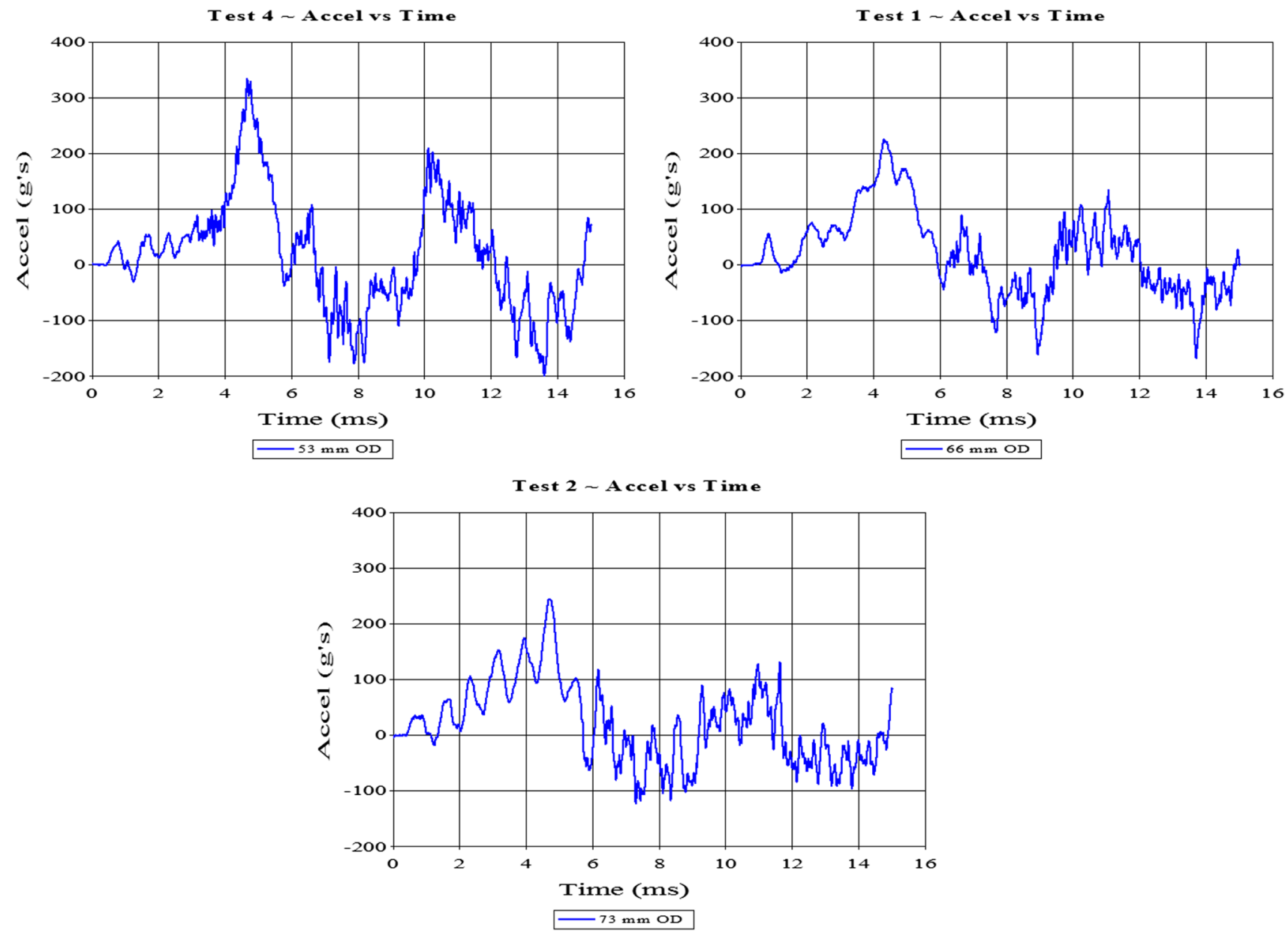

Fig. 13 Acceleration signal comparison 53, 66, and $73 \mathrm{~mm}$ outer diameter cylinders for use as mitigation

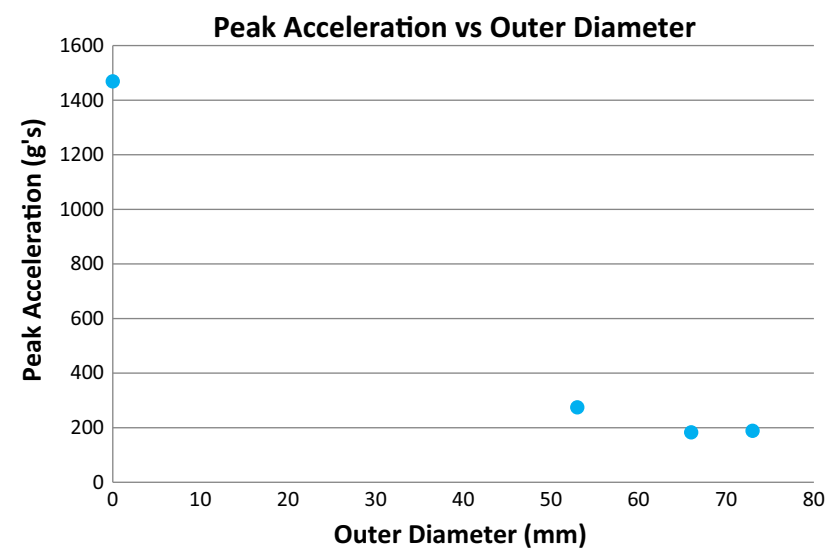

Fig. 14 The effect that increasing the outer diameter of the mitigating cylinders has on peak frame acceleration

earlier experiment that used a commercial extruded can, the second experiment used a shim stock of $0.15 \mathrm{~mm}$ thickness, and the third a shim stock of $0.2 \mathrm{~mm}$ thickness. All experiments used a HOT of $25 \mathrm{~mm}$, a charge size of
$4.4 \mathrm{~g}$ with a DOB of $10 \mathrm{~mm}$ and a SOD of $40 \mathrm{~mm}$. All used aluminum as the material. Also, for each of the experiments only four thin-walled cylinders were used for mitigation and the cylinders were only attached to the hull.

With regard to the two experiments comparing commercially produced aluminum cans to the shim stock cans, it was observed that there was no splitting of the shim stock cans at the seam. The cans crumpled as effectively as the commercially produced can as well. The results for acceleration and velocity (obtained from the first integration of the acceleration) are shown in Table 3.

It is very clear that the thin-walled cylinders produced from shim stock perform the same as the commercially produced, seamless cans. Therefore the experiment series investigating the effects of wall thickness on peak acceleration can be directly compared to the experiments studying the effects of height of target, number of cans, and outer diameter.

It was noticed from these results (in a manner similar to what was observed when the number of cylinders was increased) that as the wall thickness increases, the low 
Table 3 Results for commercial and shim stock cylinders

\begin{tabular}{|c|c|c|c|c|c|c|c|}
\hline $\begin{array}{l}\text { Test } \\
\text { number }\end{array}$ & $\begin{array}{l}\text { No of } \\
\text { cylinders }\end{array}$ & Cylinder material & $\begin{array}{l}\text { Cylinder } \\
\text { OD }(\mathrm{mm})\end{array}$ & $\begin{array}{l}\text { Cylinder wall } \\
\text { thickness(mm) }\end{array}$ & $\begin{array}{l}\text { Height of } \\
\text { target }(\mathrm{mm})\end{array}$ & $\begin{array}{l}\text { Avg peak } \\
\text { accel }(g \mathrm{~s})\end{array}$ & $\begin{array}{l}\text { Avg peak } \\
\text { velocity }(\mathrm{m} / \mathrm{s})\end{array}$ \\
\hline 1 & 4 & Aluminum (Commercial) & 66 & 0.1 & 25 & 183 & 4.225 \\
\hline 2 & 4 & Aluminum & 66 & 0.1 & 25 & 182.75 & 4.235 \\
\hline
\end{tabular}
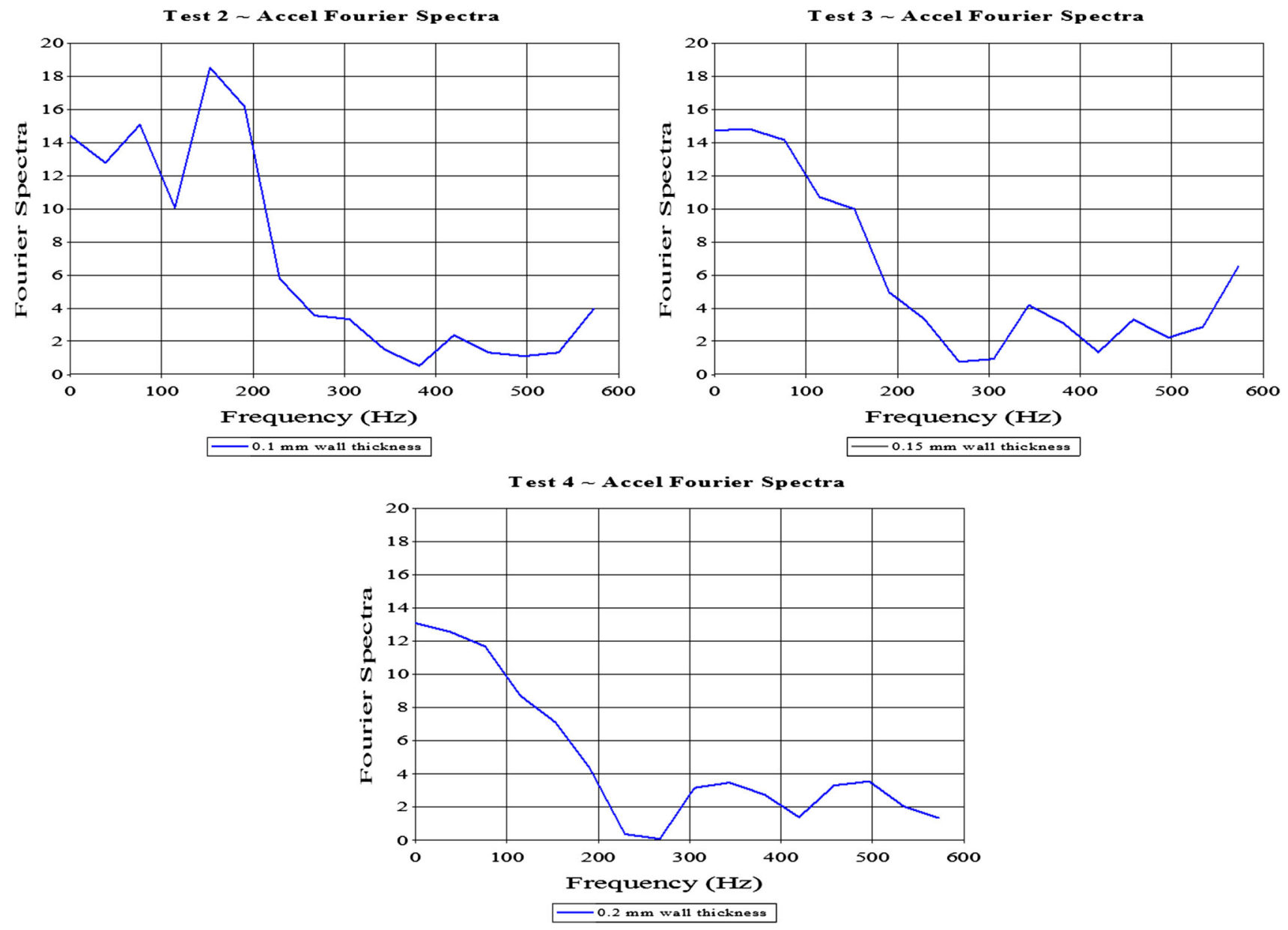

Fig. 15 Fourier spectra comparison for experiments in the wall thickness study

frequency frame vibration seems to diminish. Though it did not produce as drastic of a damping effect as increasing the number of cans, increasing the thickness of the cylinder does reduce vibrations of the frame. Figure 15 presents the Fourier Spectra of the acceleration versus time curve for each of the three wall thicknesses. Notice in Fig. 15 the weakening of the presence of low frequency frame vibrations as the walls of the cylinder become thicker.

Figure 16 shows how the peak acceleration varies as the wall thickness is changed.

The initial indication from viewing Fig. 16 is that the cylinder wall thickness has little notable effect. A minor decrease in acceleration accompanying the increase in wall thickness from 0.1 to $0.15 \mathrm{~mm}$ is directly followed by an increase of the same magnitude with an increase in wall thickness from 0.15 to $0.2 \mathrm{~mm}$. Again, we believe these slight changes in peak acceleration are within the range of data scatter, but were unable to develop this envelope due to the limited number of tests that we were capable of running.

The final result stemming from the wall thickness study comes as a visual observation. After each experiment the cylinders are inspected to make sure no tearing of the can occurred. It was noted that the cans crushed in significantly different ways as the wall thickness increased. Pictures of each of the sets of cylinders (post-experiment) are shown in 


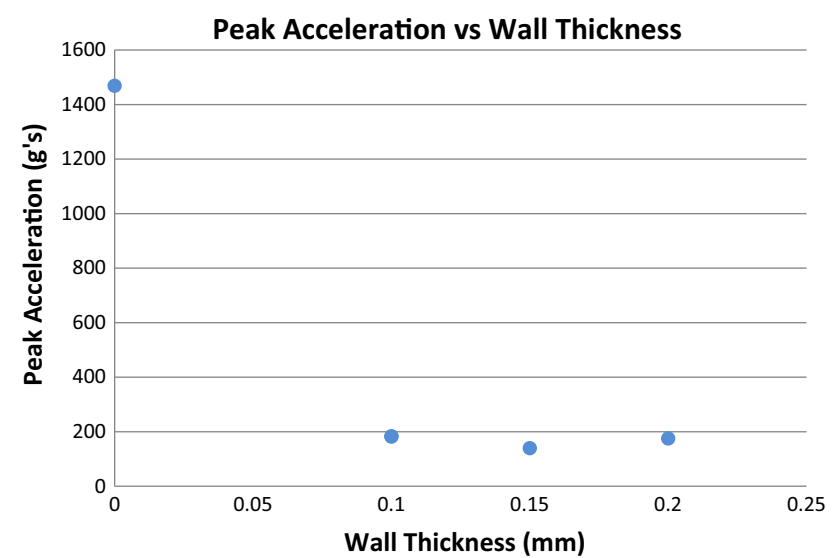

Fig. 16 The changes in peak frame acceleration as the wall thickness of the cylinders increases
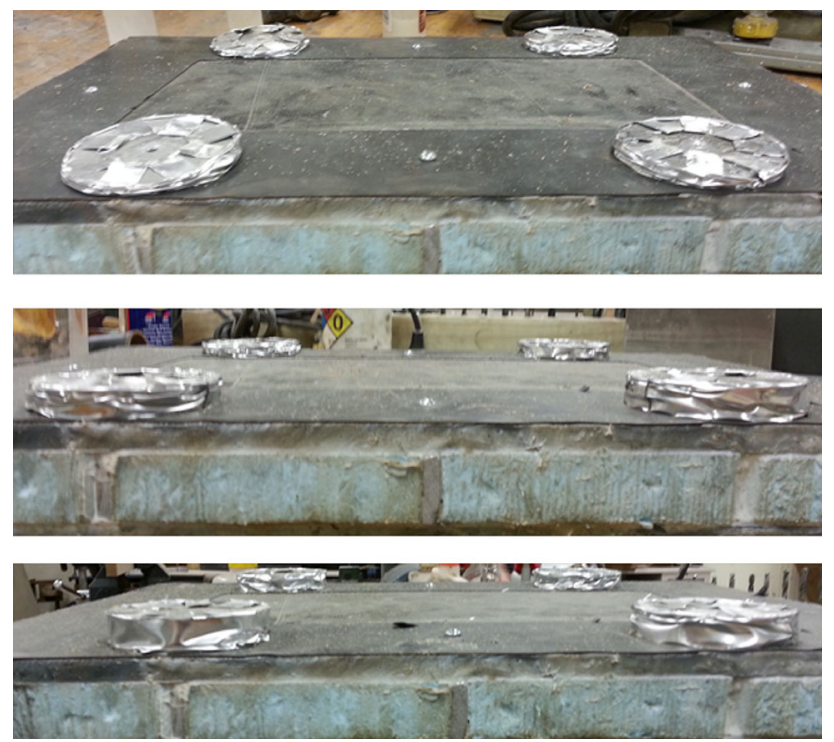

Fig. 17 Crushing characteristics of $0.1 \mathrm{~mm}$ (top) $0.15 \mathrm{~mm}$ (middle) and $0.2 \mathrm{~mm}$ (bottom) wall thickness cylinders

Fig. 17. From these photos it is noted that the $0.1 \mathrm{~mm}$ thick cylinders crushed completely with many folds in the material. The $0.15 \mathrm{~mm}$ can underwent semi-complete crushing with nice folds in the material as well. At the point when the wall thickness reached $0.2 \mathrm{~mm}$, it is noted that the cylinder does not undergo complete crushing and that there are a few large areas on the surface of the can that show little or no plastic deformation.

\section{Cylinder Material Study}

The next experiment conducted was aimed at viewing the effects of changing the metal material of the thin-walled cylinders. To accomplish this, a steel cylinder with the same wall thickness and outer diameter as one of the aluminum cylinders was created. Table 4 shows a comparison of results for two cylinders that were identical except for the material that they were made of.

From viewing the results in Table 4 , it is seen that the difference between the two cylinders is minor. The steel cylinder resulted in marginally higher peak acceleration values, likely stemming from its increased stiffness and thus higher energy transmission. Due to the fact that the steel material did not improve the mitigation levels previously obtained from the aluminum cylinders, it was decided to not go any farther in investigating other materials.

\section{Effects of Cylinder Geometry and Number of Cylinders on Impulse and Kinetic Energy}

Though not covered in detail in this paper, the change in kinetic energy and impulse of the target plate as a function of the mitigating cylinders should be mentioned.

Regardless of the various HOT scenarios tested, the impulse imparted to the frame saw a decline in the neighborhood of $15 \%$ when compared with the baseline (no mitigation) experiments. Kinetic energy decreased by close to $30 \%$, compared with the corresponding experiment with no mitigation present, for each HOT.

With six cylinders used as mitigation, the impulse decreased by approximately $25 \%$ of the value of impulse resulting from an experiment with no mitigation. A larger decrease in kinetic energy of approximately $50 \%$ occurred when using six cylinders as opposed to no mitigation.

The largest OD cylinder had a decrease in impulse of $15 \%$ compared with the impulse value obtained with no mitigation. The kinetic energy of the simulated vehicle with the largest OD cylinders declined by $30 \%$ compared to the kinetic energy from the experiment with no mitigation.

Table 4 Experiment results for cylinder material study

\begin{tabular}{|c|c|c|c|c|c|c|c|}
\hline $\begin{array}{l}\text { Test } \\
\text { number }\end{array}$ & $\begin{array}{l}\text { No of } \\
\text { cylinders }\end{array}$ & $\begin{array}{l}\text { Cylinder } \\
\text { material }\end{array}$ & $\begin{array}{l}\text { Cylinder } \\
\text { OD (mm) }\end{array}$ & $\begin{array}{l}\text { Cylinder wall } \\
\text { thickness }(\mathrm{mm})\end{array}$ & $\begin{array}{l}\text { Height of } \\
\text { target }(\mathrm{mm})\end{array}$ & $\begin{array}{l}\text { Avg peak } \\
\text { accel }(g \mathrm{~s})\end{array}$ & $\begin{array}{l}\text { Avg peak } \\
\text { velocity }(\mathrm{m} / \mathrm{s})\end{array}$ \\
\hline 1 & 4 & Aluminum (shim) & 66 & 0.1 & 25 & 183.0 & 4.2 \\
\hline 2 & 4 & Steel (Shim) & 66 & 0.1 & 25 & 203.3 & 3.8 \\
\hline
\end{tabular}




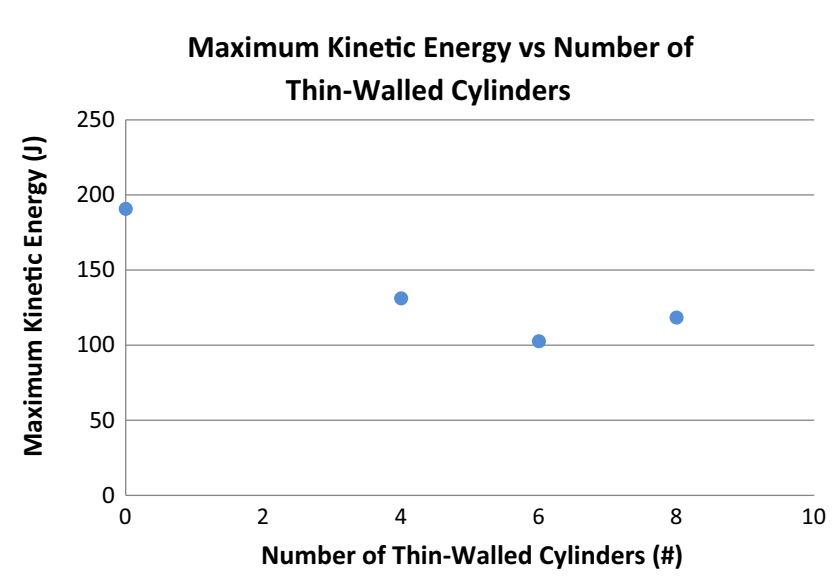

Fig. 18 Graph portraying the effect of varying the number of mitigating cylinders on the maximum kinetic energy imparted to the frame

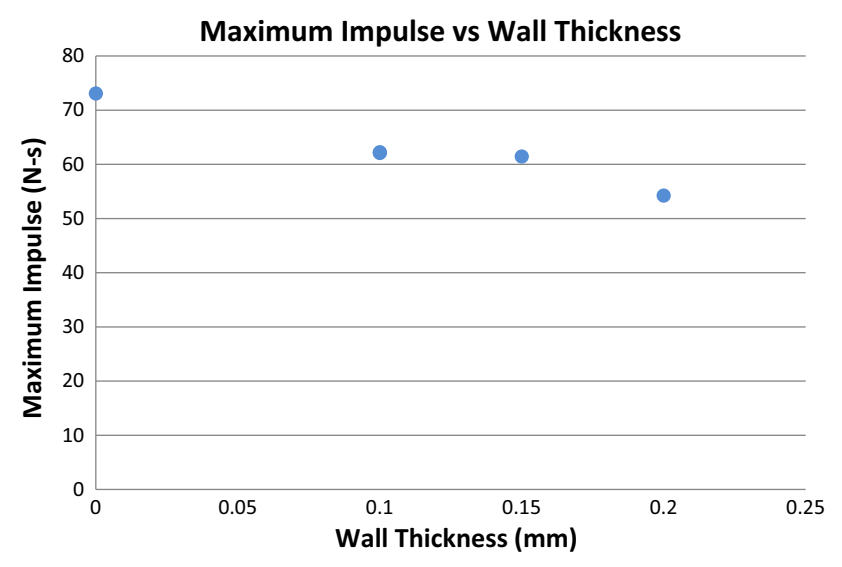

Fig. 19 Graph depicting the change in the maximum impulse of the vehicle frame as the wall thickness of the mitigating cylinder is changed

With regard to the changing of wall thickness of the cylinders, the minimum impulse occurs at a wall thickness of $0.2 \mathrm{~mm}$ and dropped $27 \%$ relative to the maximum value of impulse when no mitigation is present. Similarly, the kinetic energy is lowest for a cylinder wall thickness of $0.2 \mathrm{~mm}$ and reduced the value of the no mitigation case by $48 \%$. The complete results on kinetic energy and impulse can be found in [28]. Sample graphs displaying the change in kinetic energy and impulse as a function of cylinder properties are shown in Figs. 18 and 19.

\section{Polyurea-Coated Thin-Walled Cylinder Experiments on a Simulated Vehicle}

To conclude the experimental series, two experiments were run. Simultaneous work in the Dynamic Effects Lab [29] showed that there was immense benefit to be gained from coating thin-walled cylinders with polyurea. It was desired to make a comparison between the presumed best-case and worst-case scenarios. The first experiment involved connecting the hull of the vehicle to the frame with six solid (non-deforming) aluminum columns. This experiment served as a worse-case scenario in which there was a rigid connection between the hull and the frame. Each column was connected to both the hull and the frame. A blast experiment, using a $40 \mathrm{~mm}$ SOD and a $10 \mathrm{~mm}$ DOB with $4.4 \mathrm{~g}$ of charge was performed in the saturated sand test bed described earlier.

The second and final experiment performed for this section used six thin-walled cylinders coated with polyurea as the connecting elements between the hull and the frame. Each thin-walled cylinder was created with $0.1 \mathrm{~mm}$ aluminum shim-stock with a height of $38 \mathrm{~mm}$ and a $66 \mathrm{~mm}$ outer diameter. All six cylinders were coated with three grams of polyurea, resulting in an approximately one to one polyurea to aluminum mass ratio. It was shown in the previously published work [29] that the mass ratio of polyurea to aluminum substrate is a major determining factor in the mitigation level provided by the device. The cylinders were connected to both the hull and the frame so that the cylinders could both crush and stretch during the experiment, maximizing the amount of acceleration mitigation.

After completing these two experiments, the initial data verification step was taken to compare the displacement curve developed from the high speed video to the double integrated acceleration signal. Once the acceleration data was verified, the two acceleration time curves were compared. The acceleration curves were taken from the same accelerometer for each of the two experiments and plotted on the same graph. The comparison between the non-deforming column experiment and the polyurea-coated thinwalled cylinder experiment is shown in Fig. 20.

It is evident from looking at Fig. 20 that an immense benefit comes from using thin-walled polyurea coated cylinders as a mitigation technique. However, a drastic change in acceleration level (comparing coated with noncoated cylinders) was not seen in the simulated vehicle experiment. From viewing the data it was hypothesized that at low acceleration levels, coated and uncoated cylinders act similarly to reduce acceleration; it has since been proven [29] that only at high acceleration levels the full benefit of the coating is realized.

An additional benefit of the coating cylinders was seen, however, in that while the uncoated aluminum thin-walled cylinders crushed completely during the blast experiments (see Fig. 17), the polyurea coated cylinders crushed approximately one-half of their height during the initial blast, and recovered over $90 \%$ of their initial height by the end of the blast event (see Fig. 21). This may result in a vehicle that is structurally able to drive away from a blast. 

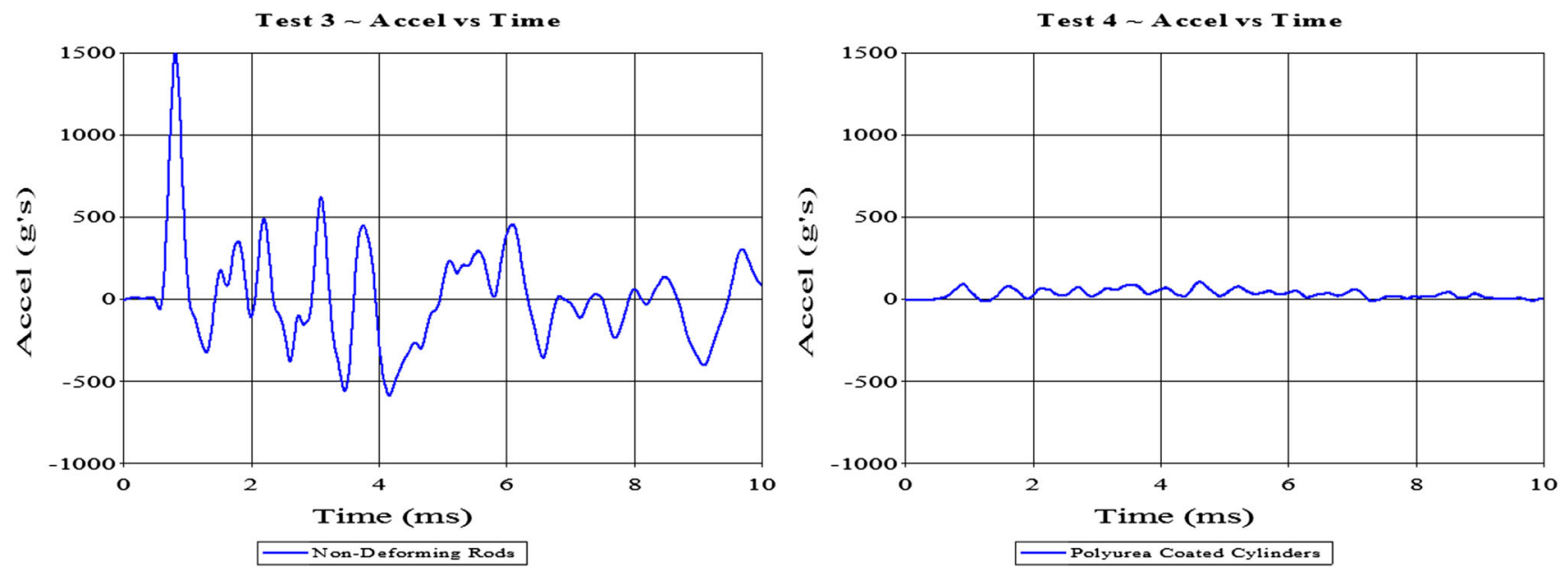

Fig. 20 Acceleration versus time comparison for non-deforming columns and polyurea-coated cylinders

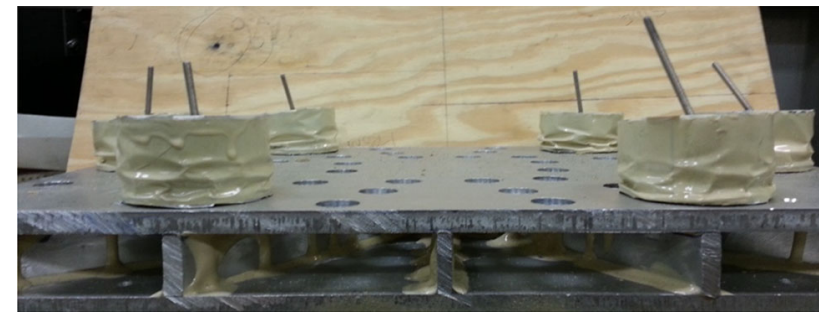

Fig. 21 Recovered height of the polyurea-coated cylinders after blast loading

\section{Discussion}

Using scaled-down representation of vehicles, the crushing of thin-walled cylinders was investigated as a means to mitigate acceleration felt by passengers located on the frame of the vehicle. A summary of the experimental findings are shown below in Table 5 .

Initially a comparison was made in between plates that were separated by various distances with air, and plates separated by the same distance of crushable aluminum.

Table 5 Tabular summary of all of the experiments run detailing the mitigation method and resulting peak acceleration of the frame

\begin{tabular}{|c|c|c|c|c|c|c|c|}
\hline Study name & $\begin{array}{l}\text { Number of } \\
\text { cylinders }\end{array}$ & $\begin{array}{l}\text { Cylinder } \\
\text { material }\end{array}$ & $\begin{array}{l}\text { Cylinder } \\
\text { OD (mm) }\end{array}$ & $\begin{array}{l}\text { Cylinder } \\
\text { ID }(\mathrm{mm})\end{array}$ & $\begin{array}{l}\text { Cylinder } \\
\text { height }(\mathrm{mm})\end{array}$ & $\begin{array}{l}\text { Attachment } \\
\text { method }\end{array}$ & $\begin{array}{l}\text { Peak frame } \\
\text { acceleration }(g \text { s) }\end{array}$ \\
\hline \multirow[t]{10}{*}{ Height of target study } & - & - & - & - & 50 & - & 1129.5 \\
\hline & - & - & - & - & 38 & - & 1458 \\
\hline & - & - & - & - & 25 & - & 1469 \\
\hline & 4 & Aluminum & 66 & 65.8 & 50 & Hull only & 103 \\
\hline & 4 & Aluminum & 66 & 65.8 & 38 & Hull only & 121.5 \\
\hline & 4 & Aluminum & 66 & 65.8 & 25 & Hull only & 189.5 \\
\hline & 4 & Aluminum & 66 & 65.8 & 25 & Hull only & 183 \\
\hline & 4 & Aluminum & 66 & 65.8 & 50 & Hull and frame & 88 \\
\hline & 4 & Aluminum & 66 & 65.8 & 38 & Hull and frame & 89 \\
\hline & 4 & Aluminum & 66 & 65.8 & 25 & Hull and frame & 163 \\
\hline \multirow[t]{2}{*}{ Number of cylinder study } & 6 & Aluminum & 66 & 65.8 & 25 & Hull only & 141.5 \\
\hline & 8 & Aluminum & 66 & 65.8 & 25 & Hull only & 150.25 \\
\hline \multirow[t]{2}{*}{ Outer diameter study } & 4 & Aluminum & 73 & 72.8 & 25 & Hull only & 188.5 \\
\hline & 4 & Aluminum & 53 & 52.8 & 25 & Hull only & 274.5 \\
\hline \multirow[t]{3}{*}{ Wall thickness study } & 4 & Aluminum & 66 & 0.1 & 25 & Hull only & 182.75 \\
\hline & 4 & Aluminum & 66 & 0.15 & 25 & Hull only & 139.5 \\
\hline & 4 & Aluminum & 66 & 0.2 & 25 & Hull only & 175.25 \\
\hline Cylinder material study & 4 & Steel & 66 & 0.1 & 25 & Hull only & 203.25 \\
\hline \multirow[t]{2}{*}{ Final tests } & 6 (non-deforming rods) & Aluminum & - & - & - & Hull and frame & 1641 \\
\hline & 6 & Aluminum & 66 & 0.1 & 38 & Hull and frame & 108 \\
\hline
\end{tabular}


With a series of $50 \mathrm{~mm}$ crushable cylinders as mitigation, the plastic deformation of the aluminum resulted in peak acceleration signals with six $\%$ of the magnitude of the original (no mitigation) experiments. Noting that a vehicle with a full-scale hull-to-frame separation of $50 \mathrm{~cm}$ is unrealistic, further experimentation was run with a separation of $25 \mathrm{~cm}$. These series of experiments varied other parameters of the cylinders such as number, outer diameter, and wall thickness and found a number of benefits.

Foremost, it was found that even at this lesser hull-toframe separation distance, the peak acceleration could be mitigated by around $90 \%$ with six cylinders of $66 \mathrm{~mm}$ OD and $59.8 \mathrm{~mm}$ ID acting as the mitigation material. Further it was found that by either adding more cylinders or increasing the wall thickness of the cylinders, the low-frequency high-amplitude vibrations of the frame could be mitigated or eliminated, thus decreasing the duration of time that a passenger undergoes severe acceleration. Finally, it was found that by coating the cylinders with a thin layer of polyurea, the same levels of mitigation could be achieved as the previously obtained mitigation through non-coated cylinders-but the cylinder only crushed $50 \%$ of its length, and (due to the material property of polyurea) recovered $90 \%$ of its pre-blast height. This result may very well lead to a vehicle that is structurally capable of driving away from an IED attack. Finally, it should be noted that this mitigation technique is applied to a vehicle without severely affecting the overall mass. To expand, the vehicle that was experimented on had a mass of $14 \mathrm{~kg}$, and the total mass of the cylinders (at their heaviest) was no more than $36 \mathrm{~g}$, which is less than $0.25 \%$ of the total mass.

As a basis for comparison, a number of mitigation techniques were tested in previous years at the Dynamic Effects Lab [22] and these studies found their best case scenario occurred using lateral crushing tubes and/or plastically deforming truss structures. With these tests, the peak acceleration was decreased by $70 \%$ with respect to their control test. An additional test was run with the crushing lateral tubes where the hull was coated with polyurea, and it was found that a $90 \%$ decrease in peak acceleration was obtained. However, it should be noted that the mass of this test was in the neighborhood of $45 \%$ greater than the mass of the control test vehicle.

\section{Conclusions}

At the beginning of this research program we desired to develop an effective means of acceleration mitigation for use on explosively loaded vehicles. To achieve the investigation of phenomena, small-scale explosive experimentation was conducted in saturated sand. Simulated vehicles and more simply shaped plate combinations were utilized to study the effects of various mitigation techniques.

It was shown in this paper that acceleration levels on simulated vehicles, reported at full-scale values, can be decreased from $150 \mathrm{~g}$ s to levels around $10 \mathrm{~g}$ s by application of thin-walled cylinders alone. With the addition of a polyurea coating to the thin-walled cylinders, at very high acceleration levels, an 80-90\% decrease in acceleration may also be obtained. Furthermore, numerous geometric properties of thin-walled cylinders were investigated showing only marginal differences to the baseline acceleration mitigation. It is believed that some combination of all of the best-case scenarios for each geometric condition, in addition to a polyurea coating, applied to the cylinders would result in a mitigation technique that would allow for complete survivability with minor injury due to the explosive event.

It was also found, though not reported in depth, that significant improvements in impulse and kinetic energy may also be made through the use of thin-walled cylinders. Previous research has been conducted in the Dynamic Effects Lab that used shaped hulls to decrease impulse on simulated vehicles to safe levels. In addition to using shaped hulls, the thin-walled cylinders may give further aid in preventing impulse related injuries to passengers in blast-loaded vehicles.

Finally, it was shown that at low acceleration levels, polyurea coated and uncoated cylinders both mitigate acceleration equally well even if the deformation of the coated cylinder was significantly less. This minimal deformation would result in a vehicle being structurally sound enough to drive away from an explosive event.

\section{References}

1. Fiskum G, Hazelton J, Gullapalli R, Fourney WL (2010) Animal model of mild brain injury caused by blast-induced hyperacceleration relevant to IED-targeted military vehicles

2. Nelson NW, Lamberty GJ, Sim AH, Doane BM (2012) Blast from the past and present: a review of blast-related injury in military personnel and veterans. In: Neuropsychological practice with veterans. p. 145

3. Fourney WL, Leiste U, Bonenberger R, Goodings DJ (2005) Mechanism of loading on plates due to explosive detonation. Fragblast 9(4):205-217

4. Taylor LC, Fourney WL, Leiste U, Genson K (2008) Geometrical shaping of vehicles for reducing impulse from buried explosions. In: Joint classified bombs/warheads \& ballistics symposium, Monterey, CA

5. Benedetti R, Fourney WL (2010) Mitigation of loading on floorboards in light armored vehicles subjected to explosive loading. University of Maryland, College Park

6. Leiste U, Fourney WL, Duff T (2013) Experimental studies to investigate pressure loading on target plates. Blast Fragm 7(2):99-126 
7. Lamb C, Schmidt M, Fitzsimmons B (2009) MRAPS, irregular warfare, and pentagon reform, vol 6. Institute for National Strategic Studies National Defense University, Washington, p 17

8. Alghamdi AAA (2001) Collapsible impact energy absorbers: an overview. Thin Walled Struct 39(2):189-213

9. Yuen SC, Nurick GN (2008) The energy-absorbing characteristics of tubular structures with geometric and material modifications: an overview. Appl Mech 61(2):020802

10. Gupta NK, Sekhon GS, Gupta PK (2005) Study of lateral compression of round metallic tubes. Thin Walled Struct 43(6):895-922

11. Shim VPW, Stronge WJ (1986) Lateral crushing in tightly packed arrays of thin-walled metal tubes. Int J Mech Sci 28(10):709-728

12. Gupta NK, Velmurugan R (1997) An analysis of axial crushing of composite tubes. J Compos Mater 31(13):1262-1286

13. Palanivelu S, Paepegem WV, Degrieck J, Vantomme J, Kakogiannis D, Ackeren JV, Hemelrijck DV, Wastiels J (2010) Comparison of the crushing performance of hollow and foamfilled small-scale composite tubes with different geometrical shapes for use in sacrificial cladding structures. Composites B 41(6):434-445

14. Palanivelu S, Van Paepegem W, Degrieck J, Van Ackeren J, Kakogiannis D, Van Hemelrijck D, Wastiels J, Vantomme J (2010) Experimental study on the axial crushing behavior of pultruded composite tubes. Polym Test 29(2):224-234

15. Palanivelu S, Van Paepegem W, Degrieck J, Reymen B, Ndambi JM, Vantomme J, Kakogiannis D, Wastiels J, Hemelrijck DV (2011) Close-range blast loading on empty recyclable metal beverage cans for use in sacrificial cladding structure. Eng Struct 33(6): 1966-1987

16. Theobald MD, Nurick GN (2007) Numerical investigation of the response of sandwich-type panels using thin-walled tubes subject to blast loads. Int J Impact Eng 34(1):134-156

17. Theobald MD, Nurick GN (2010) Experimental and numerical analysis of tube-core claddings under blast loads. Int J Impact Eng 37(3):333-348
18. Yi J, Boyce MC, Lee GF, Balizer E (2006) Large deformation rate-dependent stress-strain behavior of polyurea and polyurethanes. Polymer 47(1):319-329

19. Roland CM, Twigg JN, Vu Y, Mott PH (2007) High strain rate mechanical behavior of polyurea. Polymer 48(2):574-578

20. Tekalur SA, Shukla A, Shivakumar K (2008) Blast resistance of polyurea based layered composite materials. Compos Struct 84(3):271-281

21. Ackland K, Anderson C, Ngo TD (2013) Deformation of polyurea-coated steel plates under localized blast loading. Impact Eng 51:13-22

22. Brodrick T, Hurley R, Fourney WL (2014) Mitigation of loading on personnel in light-armored vehicles using small model testing. Blast mitigation. Springer, New York, pp 249-277

23. Fourney WL, Leiste U, Bonenberger R, Goodings DJ (2005) Explosive Impulse on plates. Fragblast 9(1):1-17

24. Taylor LC, Skaggs RR, Gault W (2005) Vertical impulse measurement of mines buried in saturated sand. Fragblast 9(1):19-28

25. Zhao X, Tiwari V, Sutton MA, Deng X, Fourney WL, Leiste U (2013) Scaling of the deformation histories for clamped circular plates subjected to buried charges. Int J Impact Eng 54(1):31-50

26. Bonsmann JM, Fourney WL (2012) An examination of the factors affecting the loading on a vehicle subjected to the detonation of a buried mine. Blast Fragm 6(3):155-180

27. HM-VK (2013) Ultra high strength handmix polyurea elastomer. http://www.specialty-products.com/pdf/tech-data/polyurea/HM-VK\% 20Preliminary.pdf. Accessed 26 Aug 2013

28. Bonsmann JM (2013) Small scale testing to study mitigation of acceleration on simulated vehicles. Dissertation, University of Maryland, College Park

29. Bonsmann JM, Fourney WL (2015) The effect of polyurea mass ratio on the acceleration mitigation capabilities of dynamically loaded structures. J Dyn Behav Mat 1(1):28 